\title{
Article \\ Critical Temperature-Humidity Index Thresholds Based on Surface Temperature for Lactating Dairy Cows in a Temperate Climate
}

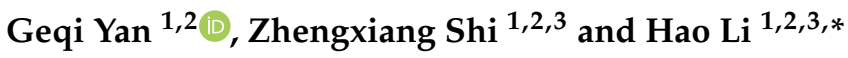 \\ 1 College of Water Resources \& Civil Engineering, China Agricultural University, Beijing 100083, China; \\ yangeqi@cau.edu.cn (G.Y.); shizhx@cau.edu.cn (Z.S.) \\ 2 Key Laboratory of Agricultural Engineering in Structure and Environment, Ministry of Agriculture and Rural \\ Affairs, Beijing 100083, China \\ 3 Beijing Engineering Research Center on Animal Healthy Environment, Beijing 100083, China \\ * Correspondence: leehcn@hotmail.com
}

check for updates

Citation: Yan, G.; Shi, Z.; Li, H. Critical Temperature-Humidity Index Thresholds Based on Surface Temperature for Lactating Dairy Cows in a Temperate Climate. Agriculture 2021, 11, 970. https:// doi.org/10.3390/agriculture11100970

Academic Editor: Eva Voslarova

Received: 15 September 2021

Accepted: 4 October 2021

Published: 6 October 2021

Publisher's Note: MDPI stays neutral with regard to jurisdictional claims in published maps and institutional affiliations.

Copyright: (c) 2021 by the authors. Licensee MDPI, Basel, Switzerland. This article is an open access article distributed under the terms and conditions of the Creative Commons Attribution (CC BY) license (https:/ / creativecommons.org/licenses/by/ $4.0 /)$.

\begin{abstract}
Detecting the early signs of heat stress is highly important in dairy farming. The surface temperature (ST) of cattle can reflect their thermal status and using such a measuring method can be efficient and non-invasive. However, few studies have reported the temperature-humidity index (THI) thresholds for ST. This study aimed to identify the critical THI thresholds for the ST of dairy cows and to evaluate the effects of the lactation stage and the lactation number. The study included 233 Holstein lactating cows from July 2020 to October 2020 in a temperate climate in China. There were 1556 records of the rectal temperature, and the maximum ST (STmax) and average ST (STave) of the head, eye, cheek, ear, neck, trunk, udder, foreleg, and hindleg were recorded. Air temperature and relative humidity were recorded to calculate the average THI. Physiological data were collected twice daily (08:00-12:00, 14:00-16:00). The critical THI thresholds were determined using the breakpoints of piecewise linear models. The significance of breakpoints was tested using the Davies test. A one-way ANOVA was used to test the effect of the lactation stage (0-60 DIM, 61-200 DIM, 201-300 DIM, DIM is days in milk) and the lactation number $(1,2,3+)$ on the THI thresholds. The results showed that the rectal temperature was significantly positively correlated with all the ST variables $(0.57 \leq \mathrm{r} \leq 0.71, p<0.01)$. The critical THI thresholds for STmax (mean of $76.1 \mathrm{THI}$, range of 73.6 to $77.9 \mathrm{THI}$ ) were significantly higher than those for STave (mean of $72.6 \mathrm{THI}$, range of 69.1 to $77.2 \mathrm{THI})(p<0.01)$. The lactation stage only significantly affected the thresholds for STmax $(p<0.05)$, and the lactation number did not significantly influence the thresholds for both STmax and STave $(p>0.05)$. This study concluded that the STave was more appropriate to define thresholds than the STmax. The threshold for the STave of the cheek (69.1 THI) was the lowest among the thresholds, indicating that the STave of the cheek could be a prior ST variable to determine critical THI thresholds. Our findings demonstrated the potential of using ST variables to define critical THI thresholds.
\end{abstract}

Keywords: heat stress; temperature-humidity index; surface temperature; infrared thermography; threshold

\section{Introduction}

Heat stress, defined as the sum of external forces acting on animals that induces an increase in core body temperature and evokes a physiological response, largely impairs the production, health, and welfare of farm animals [1,2]. Rising global temperatures combined with an increase in the number of farm animals and the intensification of agriculture makes heat stress a severe challenge facing the global dairy industry [3].

For dairy cows, early signals of heat stress can be indicated by an elevated core body temperature (e.g., rectal and vaginal temperature) [4], an increased respiration or panting 
rate [5], heart rate [6], and surface temperature [2,7]. These physiological indicators could start to abruptly rise at some environmental thresholds, which are commonly defined by the temperature-humidity index (THI). Identifying critical THI thresholds can help farm staff or inside controllers to initiate cooling systems in a timely fashion to maintain cows' productivity and ensure animal welfare. Recent studies have updated the critical THI thresholds based on physiological responses for dairy calves [8], heifers [9], and cows $[10,11]$. It is generally thought that the critical THI threshold for cows ranges from 68 to 72 [12]. Most of the critical THI thresholds were based on rectal temperature and respiration rate [9-11]. To date, there are no relevant thresholds based on the surface temperature (ST) of dairy cows reported in scientific literature.

In recent years, ST has been widely studied by the research related to cows' body temperatures and behaviors [13-17]. Much of the literature demonstrates that ST is largely associated with thermal comfort since thermoregulation requires integrative signaling between the ST and body core temperature [18-20]. It is not easy to monitor body temperature in a dairy farm on a practical level. However, using infrared thermography (IRT) to measure ST is far less labor- and time-intensive. Further, this method is non-invasive and possesses greater automation potential than body temperature measures [15,21]. Previous studies reported that ST is more sensitive and has a shorter time lag to changes in environmental conditions than body core temperature [7,22]. It can be speculated that a relatively quick increase in ST may occur at a lower THI value. A reasonable and potentially lower critical THI threshold based on ST will help dairy farms develop robust and cost-effective strategies for heat stress abatement.

Therefore, the objective of the current study was to identify the critical THI thresholds for the surface temperature of dairy cows. The surface temperatures of different body regions were recorded. Previous studies reported that the sensitivity of a cow to heat load could be influenced by some cow-related factors, including the lactation stage and the lactation number $[23,24]$. Thus, it was hypothesized that the lactation stage and number would have an effect on critical THI thresholds calculated using ST.

\section{Materials and Methods}

\subsection{Experimental Site, Cows and Housing}

The study was conducted on a commercial dairy farm, in a 3000 cow facility built in 2006. The farm was located in northern China $\left(39^{\circ} 13^{\prime} \mathrm{N}, 117^{\circ} 2^{\prime} \mathrm{E}\right)$. This region was characterized by a temperate continental monsoon climate. The study started in July 2020 and ended in October 2020. A total of 1556 records were collected from 233 Holstein lactating cows (days in milk, DIM $\leq 300$ ), which were randomly selected from the herd. Basic information on the cows is presented in Table 1.

Table 1. Description of cows used in this study.

\begin{tabular}{ccccc}
\hline Parameter & Mean & Standard Deviation & Minimum & Maximum \\
\hline Lactation number & 2.5 & 0.6 & 1 & 5 \\
Days in milk & 151.8 & 103.3 & 9 & 300 \\
Daily milk yield, kg & 37.0 & 12.3 & 1.7 & 66.6 \\
\hline
\end{tabular}

All the cows were raised in semi-closed free-stall barns, which were $107.5 \mathrm{~m}$ in length and $31.0 \mathrm{~m}$ in width and oriented in the east-west axis. The barns were equipped with 276 lying cubicles, with a mixture of sawdust and wood shavings as bedding material. The barns were naturally ventilated through the ridge openings and adjustable curtains mounted on the sidewalls. There were sprinklers and fans equipped to cool the cows in hot seasons. Because of the requirements of the study, the fans $(1.0 \mathrm{~m}$ in diameter; air amount of $25,430 \mathrm{~m}^{3} / \mathrm{h}$ ) were regularly operated (air temperature $>18^{\circ} \mathrm{C}$ on and $\leq 18{ }^{\circ} \mathrm{C}$ off), but the sprinklers were inactivated temporarily during the collection of measurements. The fans, spaced every $6.0 \mathrm{~m}$ in the long axis direction, were installed $2.7 \mathrm{~m}$ over the floor. 
The farm has two herringbone parlors. The cows were milked at 07:30, 13:30, and 19:30 daily. The herd management system (Afimilk, Kibbutz Afikim, Israel) recorded the cows' information, including milk yield, DIM, lactation number, and health status. Cows were fed a total mixed ration (TMR) three times per day (at 8:00, 14:00, and 18:00). The TMR consisted of a DM basis of $25.0 \%$ corn silage, $20.0 \%$ alfalfa hay, $20.0 \%$ flaked corn, $12.7 \%$ soybean meal, $7.0 \%$ oat hay, $3.0 \%$ cottonseed, $2.1 \%$ beet pulp, $3.9 \%$ brewer's grain, $2.0 \%$ molasses, and $4.3 \%$ premix. The remaining feed was removed at $07: 00$ every day. The cows were healthy and had free access to clean drinking water during the experimental period.

\subsection{Environmental and Animal Measures}

We carried out 60 measurements over 30 test days (2- to 4-day intervals). Measurements were conducted at 08:00-12:00 or 14:00-18:00 on each test day. Air temperature (TA) and relative humidity (RH) were recorded every 10 min using HOBO U23-001 (Onset Computer Corp., Bourne, MA, USA, with an accuracy of $\pm 0.2^{\circ} \mathrm{C}$ from -40 to $70{ }^{\circ} \mathrm{C}$ and $\pm 2.5 \%$ from $10 \%$ to $90 \%$ ). The sensor was placed at the center of the barn and $2.0 \mathrm{~m}$ above the floor throughout the duration of the experiment. TA and RH were used to calculate the THI through the following equation [25]:

$$
\mathrm{THI}=(1.8 \times \mathrm{TA}+32)-(0.55-0.0055 \times \mathrm{RH}) \times(1.8 \times \mathrm{TA}-26)
$$

The average TA, RH, and THI, which were determined by averaging all the records in one measurement, are shown in Figure 1.

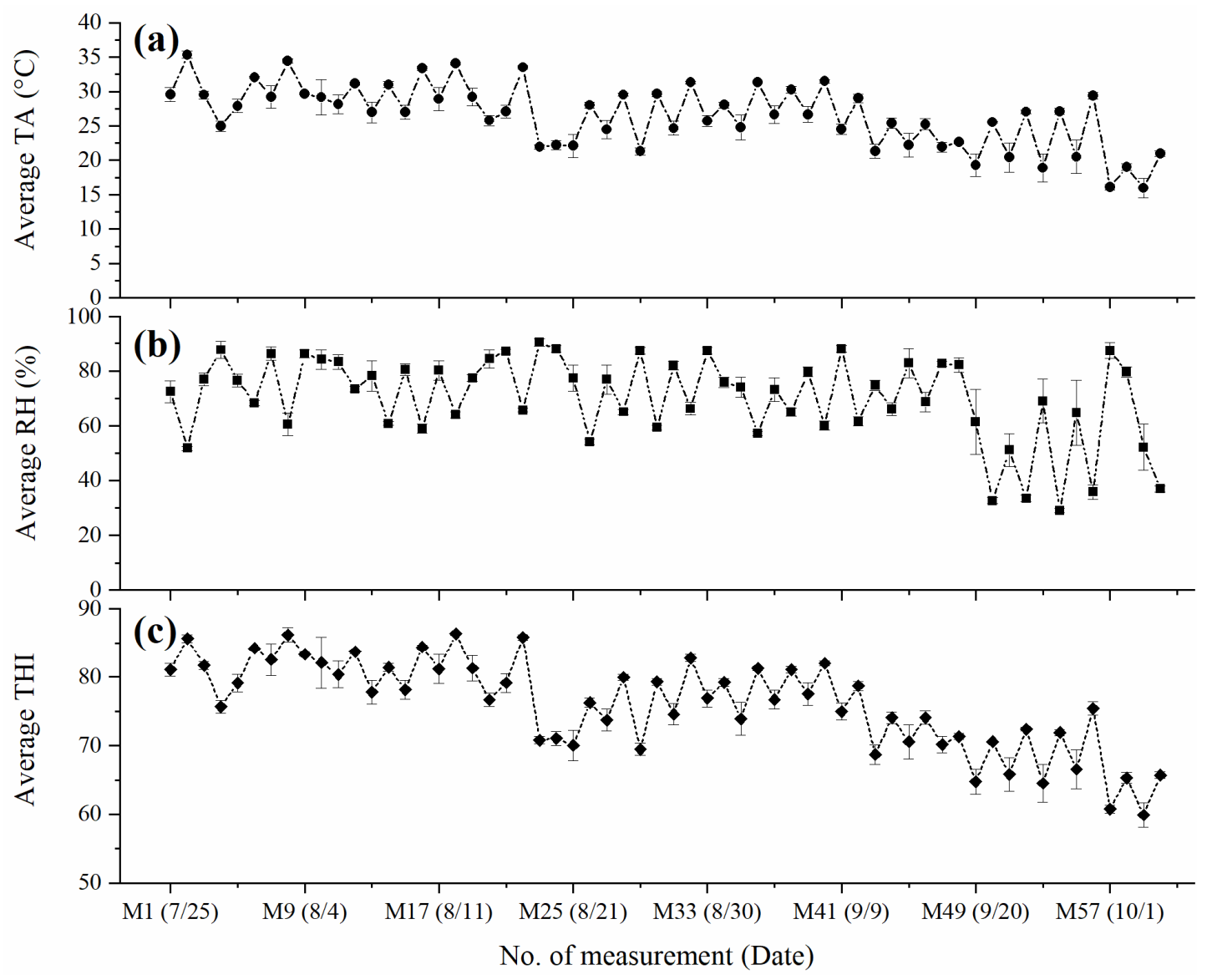

Figure 1. Variation of average $( \pm \mathrm{SD})(\mathbf{a})$ air temperature $\left(\mathrm{TA},{ }^{\circ} \mathrm{C}\right)$; $(\mathbf{b})$ relative humidity $(\mathrm{RH}, \%)$ and $(\mathbf{c})$ temperaturehumidity index (THI) of each measurement (60 measurements on 30 test days) during the experimental period (July to October 2020). The average was calculated by averaging all the records in one measurement. 
Animal measures were taken twice daily (09:00-12:00, 15:00-18:00) after milking the cows. Each measurement contained 25-30 cows that were randomly selected from the stall (252 cows). Rectal temperatures were measured using a veterinary thermometer (ShangNong Technology Inc., Qingdao, Shandong, China). After obtaining the rectal temperature measurement, surface temperatures were measured using an infrared camera (Fotric 235, Fortic Inc., Jingan, Shanghai, China). The camera is of scientific grade, has $336 \times 252$ pixels, thermal sensitivity of $<0.06^{\circ} \mathrm{C}$, and a temperature range of -20 to $150{ }^{\circ} \mathrm{C}$. The infrared images were acquired from the side of the body facing away from the fans. There was a fixed distance of $1.5 \mathrm{~m}$ between the cow and the observer [26]. Analyses of the infrared images were performed using AnalyzIR software (Fortic Inc., Jingan, Shanghai, China). In this software, the emissivity was kept at 0.97 [26]. Additionally, the imaging distance can be fine-tuned when using the software to mitigate its effect on the results of the surface temperature. Figure 2 shows a typical example of the images of body locations (or regions) in this study. The locations were in accordance with previous studies [26-28]. There are two valuable temperature variables, i.e., maximum ST (STmax) and average ST (STave), recorded in a region on an infrared image (Figure 2). In this study, the investigated body locations included the head, eye, ear, cheek, neck, trunk, udder, foreleg, and hindleg. For each location, rather than using the shape-drawing tool, we more often outlined the region of the head, ear, udder, foreleg, and hindleg using a polygon. The cheek and trunk were outlined using a rectangle. The eye was outlined using an ellipse. The shapes that were used also agreed with the previous literature on ST assessments using infrared imaging in cattle [26-29]. The software automatically computed the STmax and STave of the region.

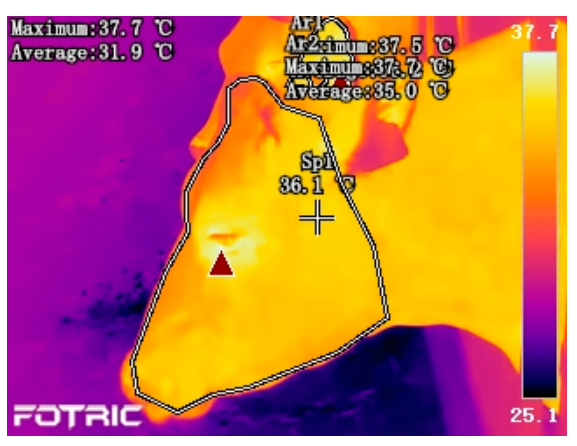

(a)

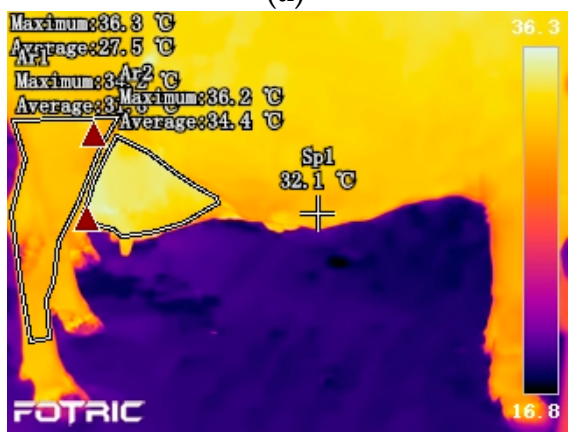

(d)

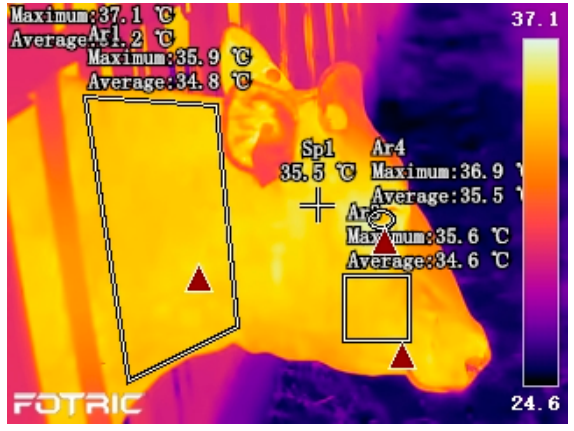

(b)

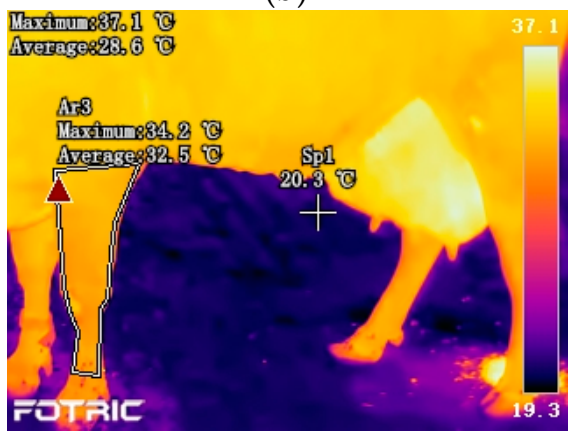

(e)

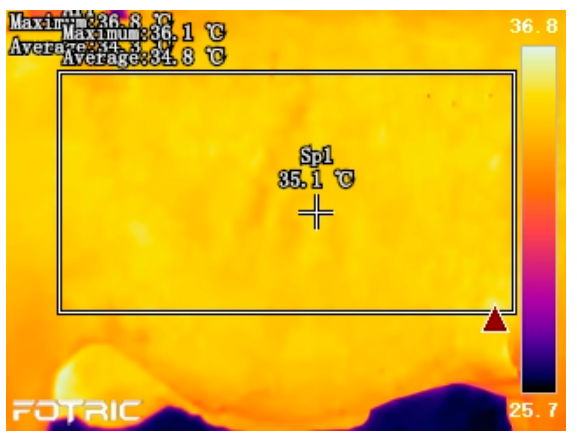

(c)

Figure 2. Infrared images and drawings of the body regions evaluated in this study. (a): head, ear; (b): eye, cheek, neck; (c): trunk; (d): udder, hindleg; (e): foreleg.

\subsection{Statistical Analysis}

All statistical analyses were performed in R 4.0.3 (R Core Team, Vienna, Austria). The coefficient of determination $\left(R^{2}\right)$ and Pearson's correlation coefficient were used to evaluate 
the relationships between the ST variables and rectal temperature. Critical THI thresholds were determined using piecewise linear regression [8-11,30], expressed as:

$$
\mathrm{Y}=\beta_{0}+\beta_{1} * \mathrm{x}+\beta_{2} *(\mathrm{x}-\mathrm{bp}){ }^{*} \mathrm{~J}+\varepsilon
$$

where $Y$ is the observation, $x$ is the average THI of each measurement, $\beta_{0}$ is the intercept, $\beta_{1}$ is the left slope, $\beta_{2}$ is the difference in slopes (i.e., right slope minus left slope), bp is the THI breakpoint (i.e., threshold), $\varepsilon$ is the random error, and J is equal to 1 when $x \geq b p$ and equal to 0 when $x<b p$. The significance of breakpoints was tested using the Davies test $\left(\mathrm{H}_{0}: \beta_{2}=0\right)$ [31]. The R package, "segmented", was provided by Muggeo et al. [31]. The normality of breakpoint data was tested using the Shapiro-Wilk test. The differences between thresholds for STmax and STave were evaluated using the paired $t$-test. The effects of the lactation stage and number on THI thresholds were studied by performing a one-way ANOVA:

$$
\mathrm{Y}_{\mathrm{ij}}=\mu+\mathrm{F}_{\mathrm{i}}+\varepsilon_{\mathrm{ij}}
$$

where $Y_{i j}$ is the jth breakpoint for STmax or STave $(j=1,2, \ldots, 9), \mu$ is the overall mean, $F_{i}$ is the fixed effect of the ith level of the factor $(i=1,2,3$; lactation stage: early-lactation $=0-60 \mathrm{DIM}$, mid-lactation $=61-200 \mathrm{DIM}$, late-lactation $=201-300 \mathrm{DIM}$; lactation number: $1,2,3+), \varepsilon_{\mathrm{ij}}$ is the random error. Pairwise comparisons among the factor levels were performed using the least significant difference (LSD) method when significance was found. The significance level in this study was set at $p<0.05$.

\section{Results}

\subsection{Association between Rectal Temperature and Surface Temperature}

Table 2 shows the relationship between the mean rectal temperature and the mean $\mathrm{ST}$. The rectal temperature explained $32-51 \%$ of the total variance in the ST variable. The coefficients of determination $\left(R^{2}\right)$ for the ST of the cheek were the highest $\left(R^{2}\right.$ of 0.48 for STmax and 0.51 for STave, respectively). The rectal temperature was significantly positively correlated with all the ST variables $(0.57 \leq \mathrm{r} \leq 0.71, p<0.01)$.

Table 2. Relationship between rectal temperature (RT) and maximum (STmax) and average surface temperature (STave) of

\begin{tabular}{|c|c|c|c|c|c|c|}
\hline \multirow[t]{2}{*}{ Body Region } & \multicolumn{3}{|c|}{ Relationship between STmax and RT } & \multicolumn{3}{|c|}{ Relationship between STave and RT } \\
\hline & Relation & $\mathbf{R}^{2}$ & Pearson $\mathbf{r}$ & Relation & $\mathbf{R}^{2}$ & Pearson $r$ \\
\hline Head $(N=1565)$ & $\mathrm{STmax}=1.09 \mathrm{RT}-5.87$ & 0.33 & 0.579 & STave $=2.77 \mathrm{RT}-74.67$ & 0.46 & 0.677 \\
\hline Eye $(N=1565)$ & $\mathrm{STmax}=1.09 \mathrm{RT}-5.82$ & 0.32 & 0.566 & STave $=1.53 \mathrm{RT}-24.54$ & 0.41 & 0.644 \\
\hline Cheek $(\mathrm{N}=1565)$ & $\mathrm{STmax}=2.42 \mathrm{RT}-59.92$ & 0.48 & 0.694 & STave $=2.92 \mathrm{RT}-80.92$ & 0.51 & 0.711 \\
\hline Ear $(N=1565)$ & $\mathrm{STmax}=2.01 \mathrm{RT}-42.89$ & 0.45 & 0.670 & STave $=2.38 \mathrm{RT}-58.56$ & 0.48 & 0.696 \\
\hline $\operatorname{Neck}(\mathrm{N}=1565)$ & $\mathrm{STmax}=2.21 \mathrm{RT}-51.64$ & 0.43 & 0.655 & STave $=2.55 \mathrm{RT}-65.81$ & 0.45 & 0.668 \\
\hline Trunk $(\mathrm{N}=1565)$ & $\mathrm{STmax}=2.18 \mathrm{RT}-49.82$ & 0.45 & 0.671 & STave $=2.45 \mathrm{RT}-61.68$ & 0.47 & 0.686 \\
\hline Udder $(\mathrm{N}=1565)$ & $\mathrm{STmax}=1.59 \mathrm{RT}-25.33$ & 0.42 & 0.648 & STave $=2.31 \mathrm{RT}-54.79$ & 0.49 & 0.702 \\
\hline Foreleg $(\mathrm{N}=1565)$ & $\mathrm{STmax}=2.42 \mathrm{RT}-60.99$ & 0.41 & 0.639 & STave $=3.02 \mathrm{RT}-86.12$ & 0.46 & 0.675 \\
\hline Hindleg $(N=1565)$ & $\mathrm{STmax}=2.47 \mathrm{RT}-62.48$ & 0.41 & 0.649 & STave $=3.15 \mathrm{RT}-90.73$ & 0.46 & 0.681 \\
\hline
\end{tabular}
different body regions.

Note: $\mathrm{N}$ means the number of records, and $\mathrm{R}^{2}$ means the coefficient of determination. $p<0.001$ for all relationships.

\subsection{THI Thresholds for Maximum and Average Surface Temperature}

Figure 3 shows the relationships between the average THI and the STmax of different body regions. The $R^{2}$ was between 0.38 and 0.71 . The highest $R^{2}$ was for the regression model between the average THI and the STmax of the cheek (Figure 4c). A significant difference in slope change was found for all the piecewise models $(p<0.001)$. 


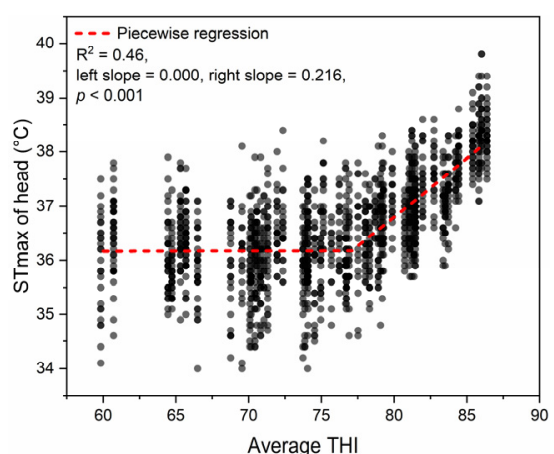

(a) Head

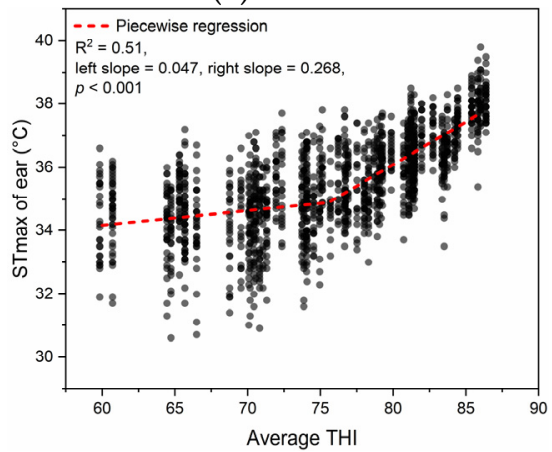

(d) Ear

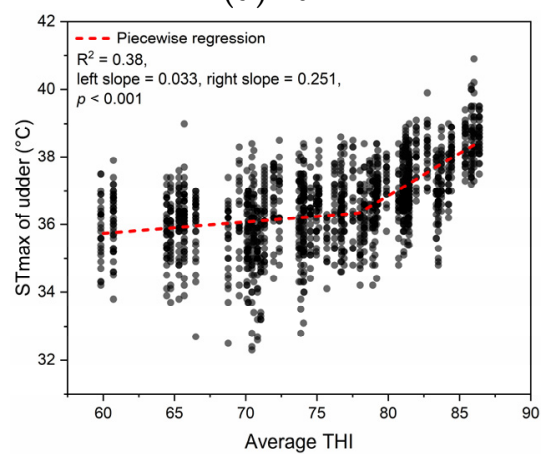

(g) Udder

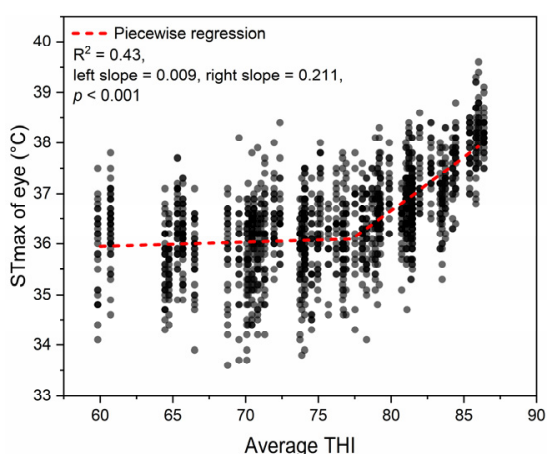

(b) Eye

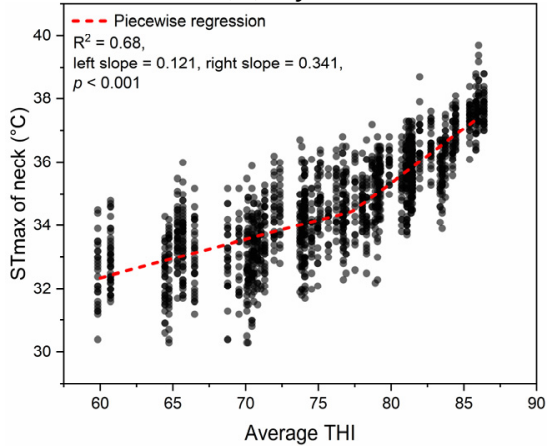

(e) Neck

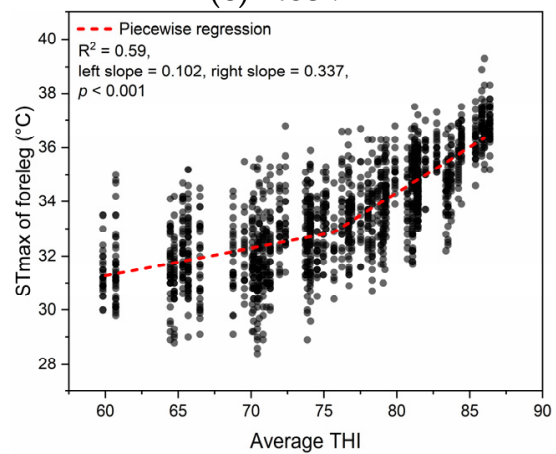

(h) Foreleg

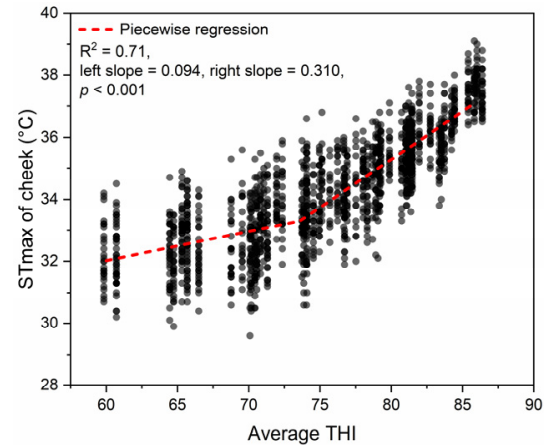

(c) Cheek

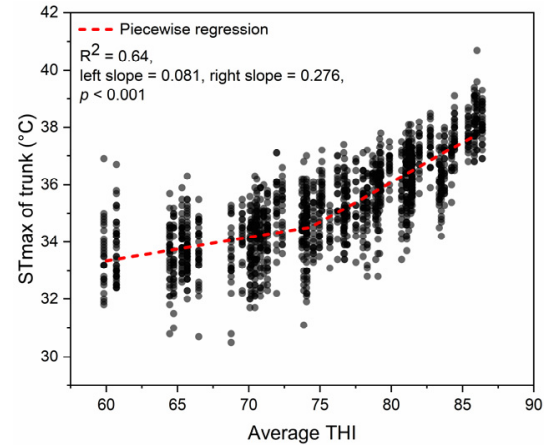

(f) Trunk

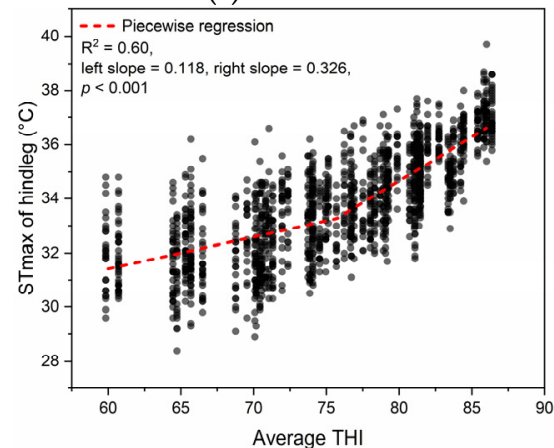

(i) Hindleg

Figure 3. Relationship between maximum surface temperature (STmax) of (a) head, (b) eye, (c) cheek, (d) ear, (e) neck, (f) trunk, (g) udder, (h) foreleg, and (i) hindleg and average THI (average of each measurement).

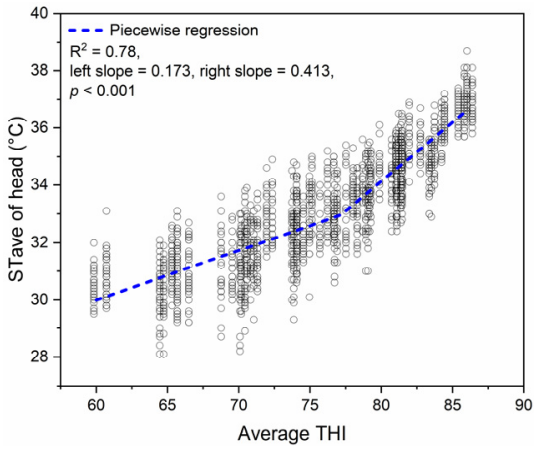

(a) Head

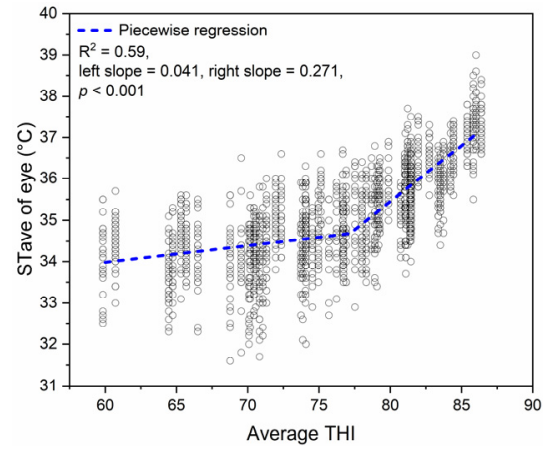

(b) Eye

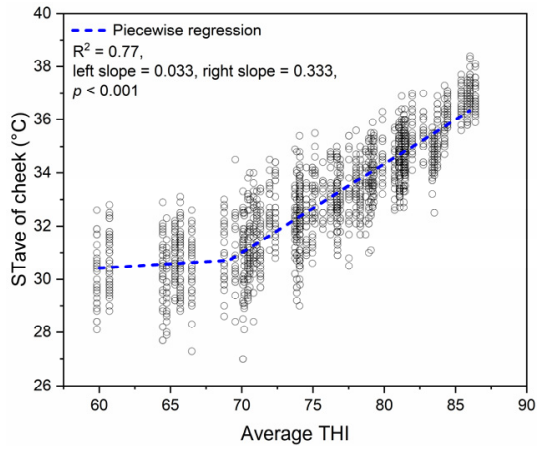

(c) Cheek

Figure 4. Cont. 


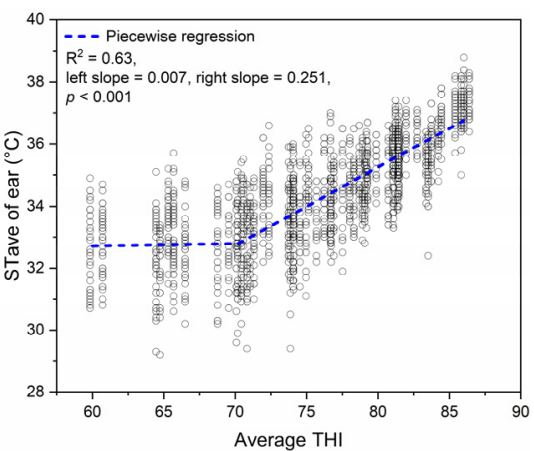

(d) Ear

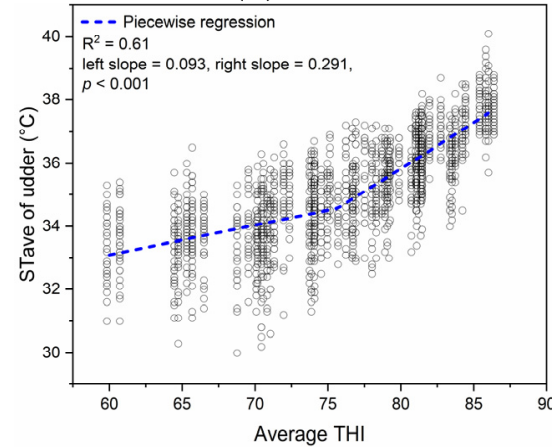

(g) Udder

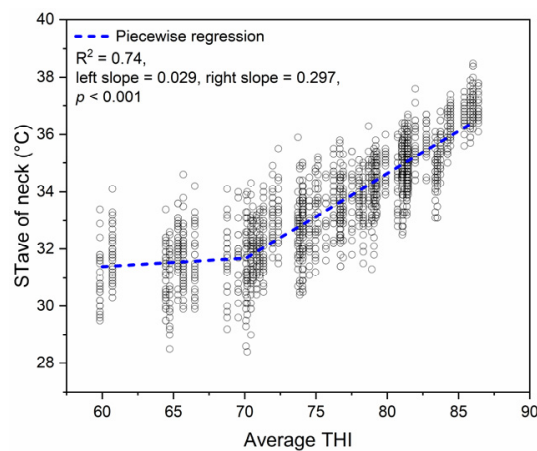

(e) Neck

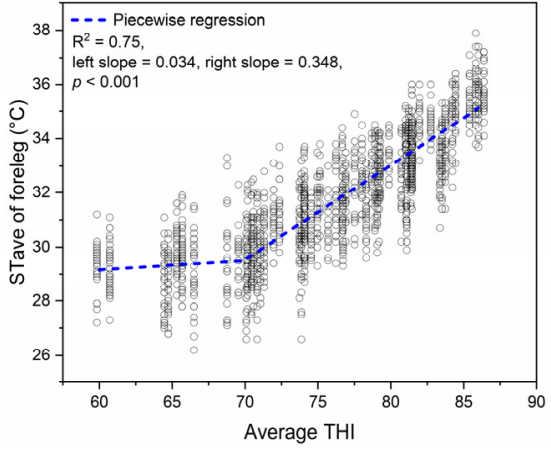

(h) Foreleg

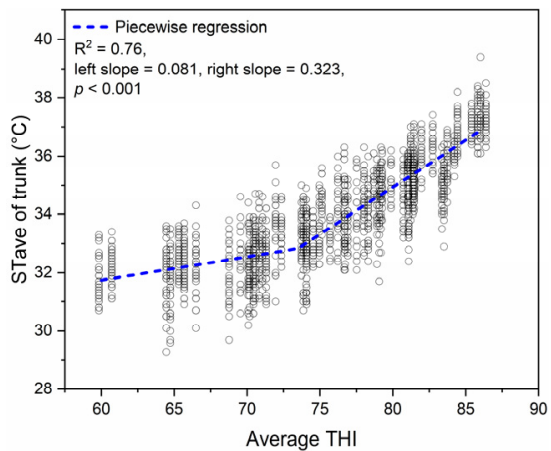

(f) Trunk

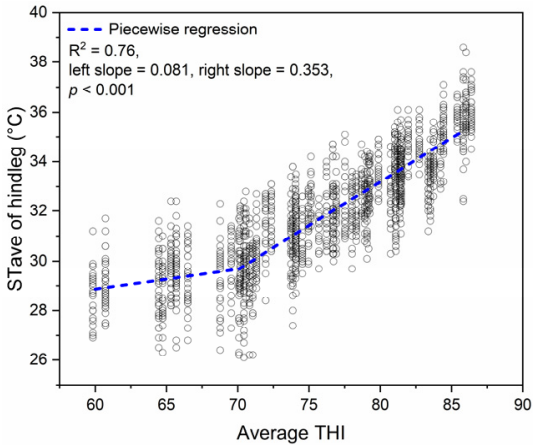

(i) Hindleg

Figure 4. Relationship between average surface temperature (STave) of (a) head, (b) eye, (c) cheek, (d) ear, (e) neck, (f) trunk, (g) udder, (h) foreleg, and (i) hindleg and average THI (average of each measurement).

Figure 4 shows the relationships between the average THI and the STave of different body regions. The $R^{2}$ was between 0.59 and 0.78 . The highest $R^{2}$ was for the regression model between the average THI and the STave of the head (Figure 5a). A significant difference in slope change was found for all the piecewise models $(p<0.001)$.

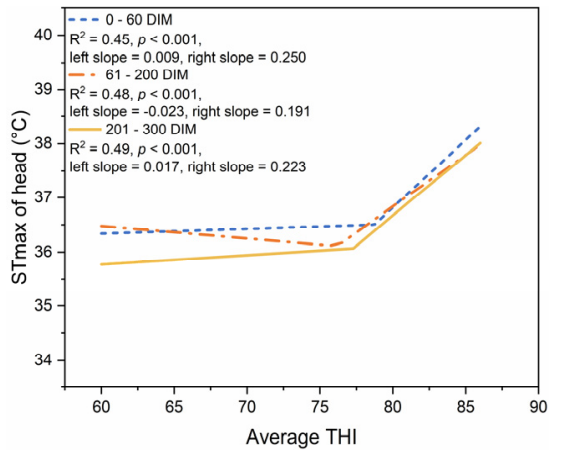

(a) Head

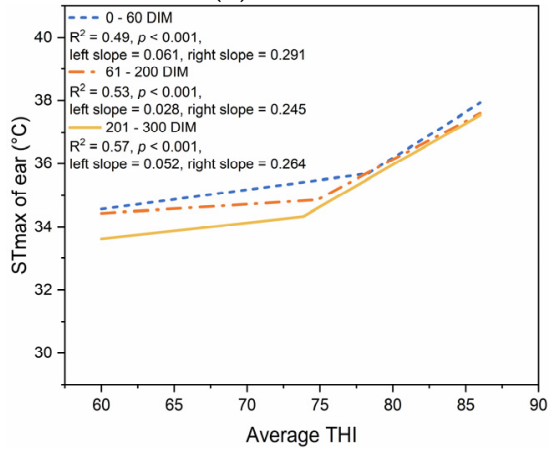

(d) Ear

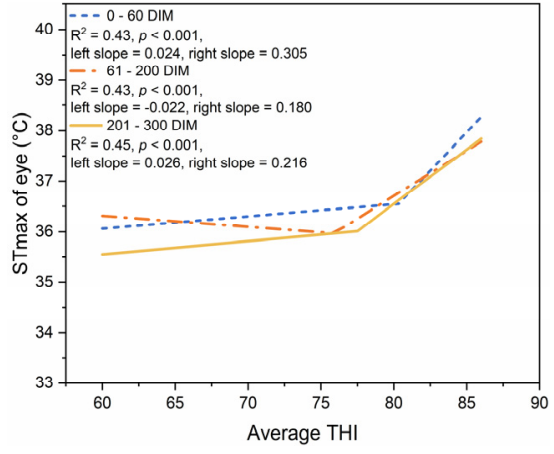

(b) Eye

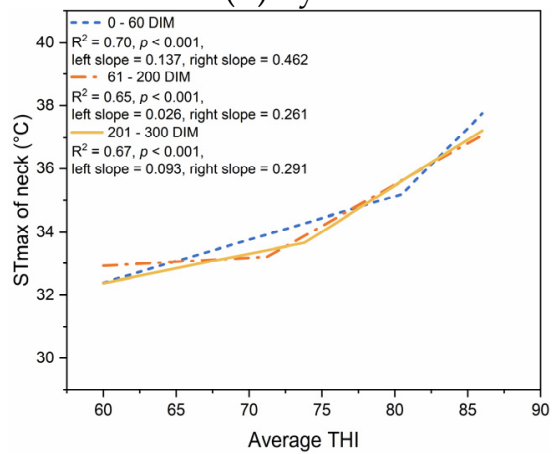

(e) Neck

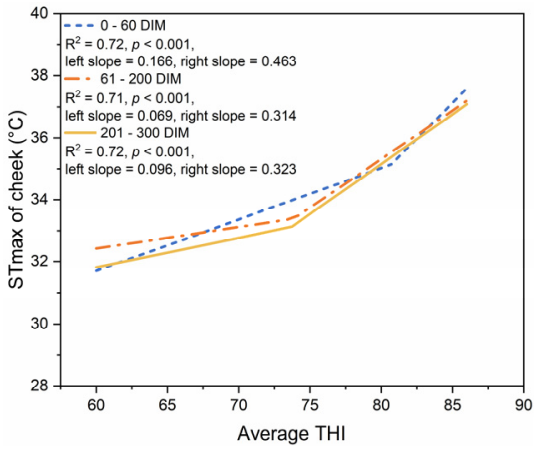

(c) Cheek

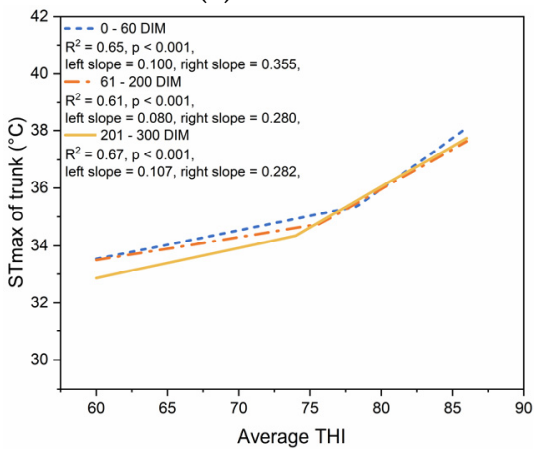

(f) Trunk

Figure 5. Cont. 


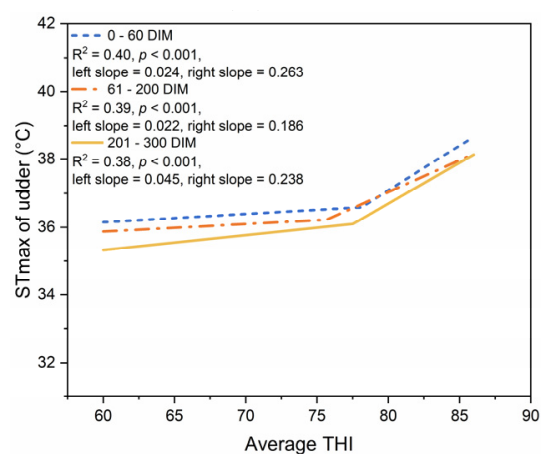

(g) Udder

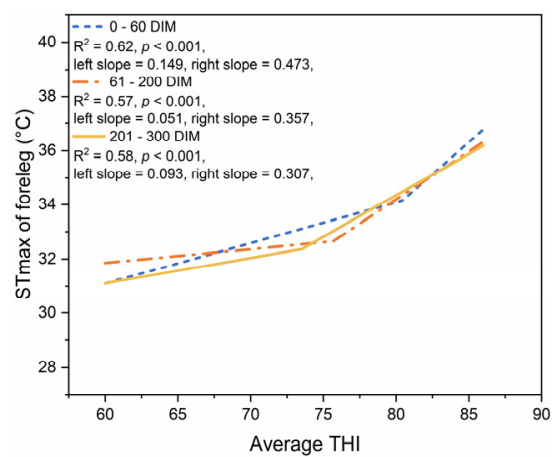

(h) Foreleg

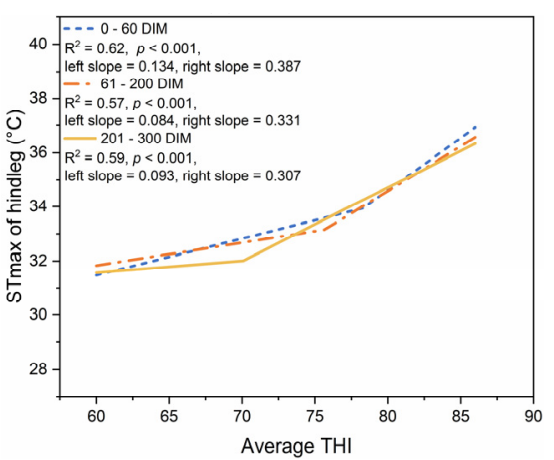

(i) Hindleg

Figure 5. Relationship between maximum surface temperature (STmax) of (a) head, (b) eye, (c) cheek, (d) ear, (e) neck, (f) trunk, (g) udder, (h) foreleg, and (i) hindleg and average THI (average of each measurement) considering lactation stage (0-60 DIM, 61-200 DIM, and 201-300 DIM).

The THI breakpoints in Figures 3 and 4 are listed in Table 3. The THI breakpoints $(76.1 \pm 1.5$, mean \pm SD) for STmax are significantly higher than those $(72.6 \pm 3.4$, mean \pm SD) for STave ( $\mathrm{t}$-value $=3.787, \mathrm{df}=8, p=0.005$ ). The lowest THI breakpoint for ST was found at the cheek (73.6 for STmax and 69.1 for STave, respectively).

Table 3. Estimates ( \pm SE) of THI breakpoint for maximum surface temperature (STmax) and average surface temperature (STave) of different body regions.

\begin{tabular}{ccc}
\hline Body Region & THI Breakpoint for STmax & THI Breakpoint for STave \\
\hline Head & $77.1 \pm 0.3$ & $77.2 \pm 0.4$ \\
Eye & $77.3 \pm 0.3$ & $77.2 \pm 0.3$ \\
Cheek & $73.6 \pm 0.5$ & $69.1 \pm 0.5$ \\
Ear & $75.6 \pm 0.5$ & $70.2 \pm 0.5$ \\
Neck & $77.3 \pm 0.4$ & $70.1 \pm 0.5$ \\
Trunk & $74.3 \pm 0.5$ & $73.5 \pm 0.4$ \\
Udder & $77.9 \pm 0.4$ & $75.7 \pm 0.5$ \\
Foreleg & $75.7 \pm 0.5$ & $69.9 \pm 0.5$ \\
Hindleg & $75.7 \pm 0.6$ & $70.1 \pm 0.6$ \\
\hline
\end{tabular}

3.3. Effect of Lactation Stage on THI Thresholds for Maximum and Average Surface Temperature

Figures 5 and 6 show the relationships between the average THI, STmax, and STave of cows in different stages of lactation. A significant breakpoint was found for all piecewise regression models $(p<0.001)$.

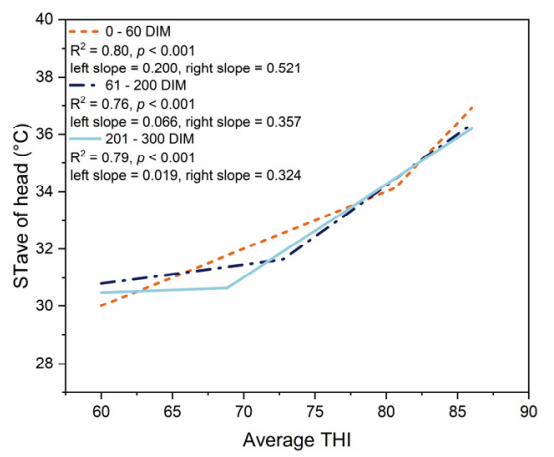

(a) Head

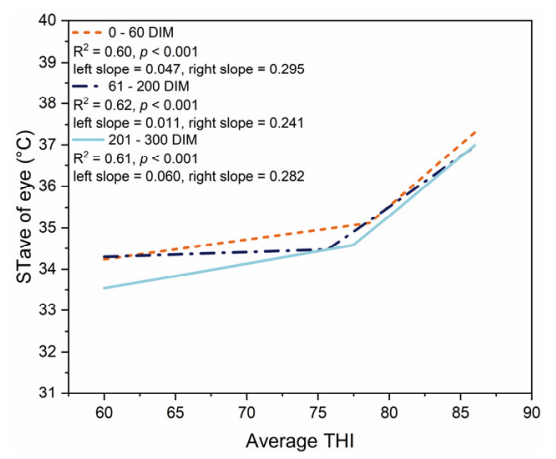

(b) Eye

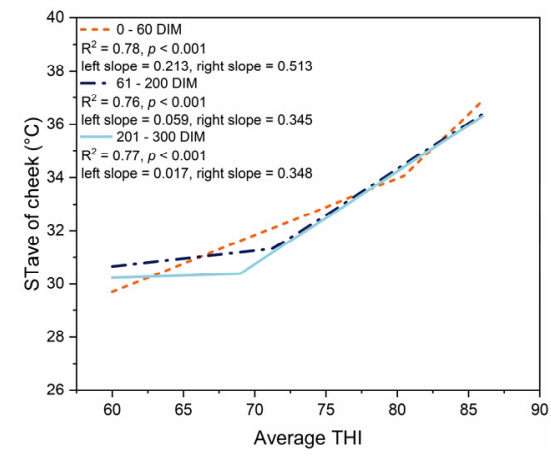

(c) Cheek

Figure 6. Cont. 


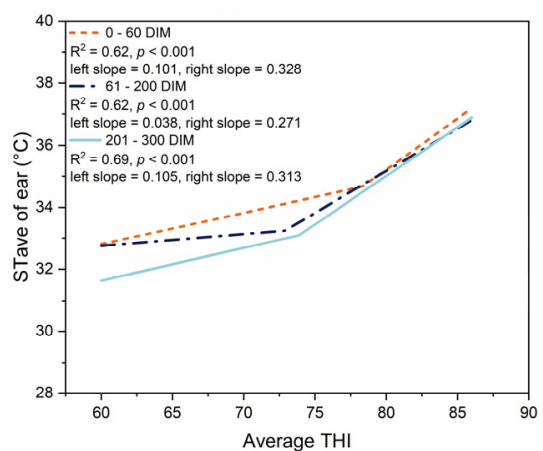

(d) Ear

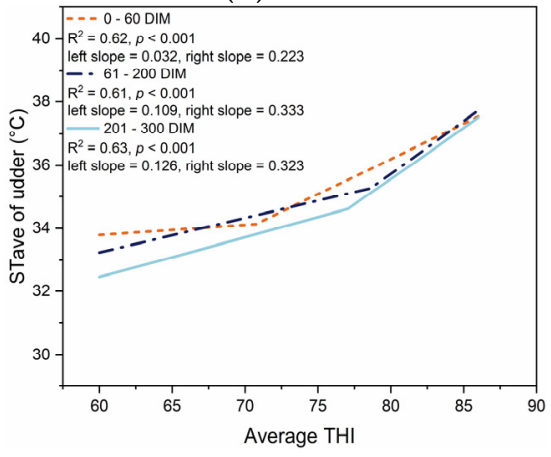

(g) Udder

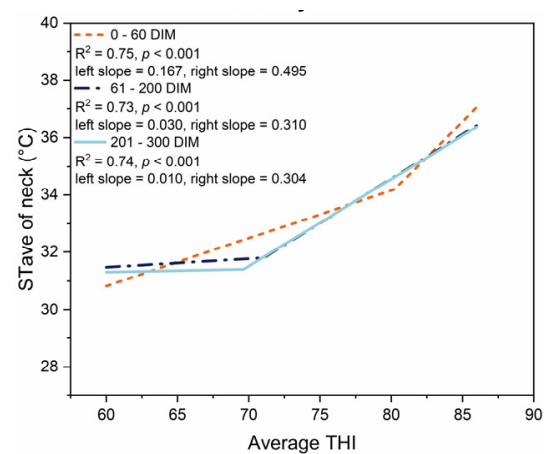

(e) Neck

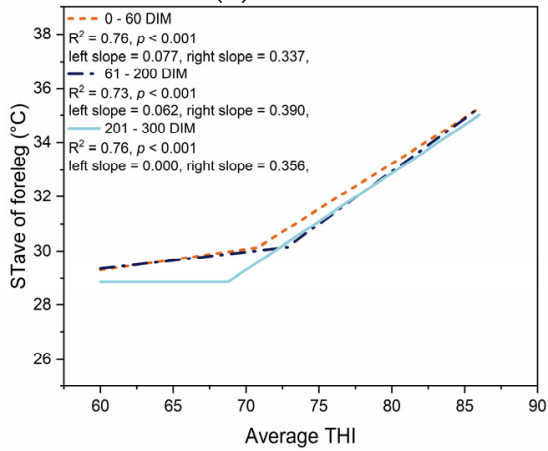

(h) Foreleg

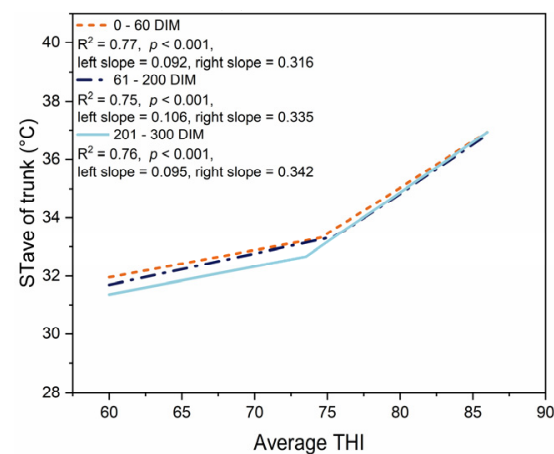

(f) Trunk

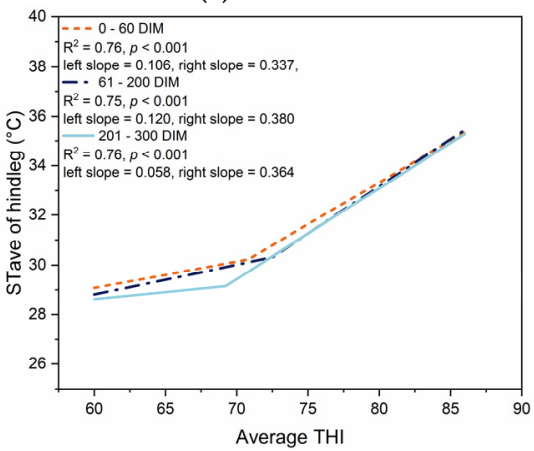

(i) Hindleg

Figure 6. Relationship between average surface temperature (STave) of (a) head (b) eye, (c) cheek, (d) ear, (e) neck, (f) trunk, (g) udder, (h) foreleg, and (i) hindleg and average THI (average of each measurement) considering lactation stage (0-60 DIM, 61-200 DIM, and 201-300 DIM).

The THI breakpoints are listed in Table 4. A one-way ANOVA analysis indicated that the stage of lactation significantly influenced the THI breakpoints for STmax (F-value $=18.801$, $\mathrm{df} 1=2$, df2 = 24, $p<0.001)$. Early-lactation cows showed higher THI breakpoints for STmax $(79.3 \pm 0.4$, mean \pm SE) than mid-lactation $(75.0 \pm 0.5$, mean \pm SE) and late-lactation cows $(74.6 \pm 0.8$, mean \pm SE) $(p<0.05)$. No significant difference in the THI breakpoints for STmax was detected between mid-lactation and late-lactation cows $(p>0.05)$. However, the stage of lactation did not show a significant effect on the THI breakpoints for STave $(\mathrm{F}-\mathrm{value}=3.088, \mathrm{df} 1=2, \mathrm{df} 2=24, p=0.064)$.

Table 4. THI breakpoints for maximum (STmax) and average surface temperature (STave) of the different body regions in early-lactation, mid-lactation, and late-lactation cows.

\begin{tabular}{ccccc}
\hline THI Breakpoint & Body Region & Early-Lactation $^{\mathbf{1}}$ & Mid-Lactation $^{\mathbf{1}}$ & Late-Lactation $^{\mathbf{1}}$ \\
\hline & Head & $78.7 \pm 0.5$ & $76.2 \pm 0.6$ & $77.3 \pm 0.5$ \\
& Eye & $80.3 \pm 0.4$ & $75.9 \pm 0.7$ & $77.5 \pm 0.5$ \\
& Cheek & $80.7 \pm 0.5$ & $73.9 \pm 0.9$ & $73.7 \pm 0.6$ \\
Ear & $78.3 \pm 0.7$ & $74.8 \pm 1.0$ & $73.9 \pm 0.7$ \\
STmax & Neck & $80.5 \pm 0.5$ & $71.2 \pm 1.1$ & $73.8 \pm 0.7$ \\
& Trunk & $78.3 \pm 0.7$ & $75.7 \pm 1.0$ & $74.0 \pm 0.8$ \\
& Udder & $78.1 \pm 0.7$ & $75.7 \pm 1.2$ & $77.5 \pm 0.7$ \\
& Foreleg & $80.4 \pm 0.6$ & $75.7 \pm 0.9$ & $73.5 \pm 0.9$ \\
& Hindleg & $78.3 \pm 0.8$ & $75.7 \pm 1.1$ & $70.1 \pm 1.1$ \\
\hline
\end{tabular}


Table 4. Cont.

\begin{tabular}{ccccc}
\hline THI Breakpoint & Body Region & Early-Lactation $^{\mathbf{1}}$ & Mid-Lactation $^{\mathbf{1}}$ & Late-Lactation $^{\mathbf{1}}$ \\
\hline & Head & $80.7 \pm 0.5$ & $72.8 \pm 0.9$ & $68.8 \pm 0.6$ \\
& Eye & $78.6 \pm 0.5$ & $75.7 \pm 0.7$ & $77.5 \pm 0.5$ \\
& Cheek & $70.5 \pm 0.6$ & $71.3 \pm 0.9$ & $69.0 \pm 0.6$ \\
STave & Ear & $78.3 \pm 0.7$ & $72.9 \pm 1.1$ & $73.9 \pm 0.7$ \\
& Neck & $80.2 \pm 0.5$ & $71.1 \pm 0.9$ & $69.6 \pm 0.6$ \\
& Trunk & $74.5 \pm 0.6$ & $75.6 \pm 0.8$ & $73.5 \pm 0.5$ \\
& Udder & $70.7 \pm 0.8$ & $78.6 \pm 0.8$ & $77.1 \pm 0.8$ \\
& Foreleg & $70.8 \pm 0.7$ & $72.8 \pm 0.9$ & $68.8 \pm 0.6$ \\
& Hindleg & $70.8 \pm 0.8$ & $72.5 \pm 1.1$ & $69.2 \pm 0.8$ \\
\hline
\end{tabular}

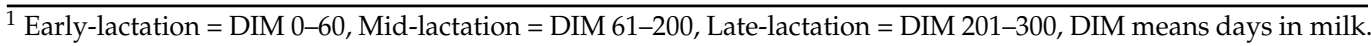

\subsection{Effect of Lactation Number on THI Thresholds for Maximum and Average} Surface Temperature

Figures 7 and 8 show the relationships between the average THI, STmax, and STave of cows for different lactation numbers.

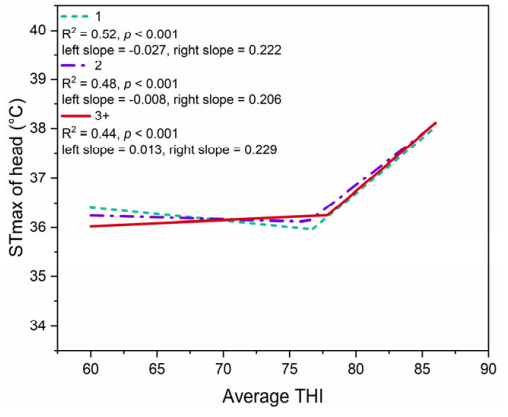

(a) Head

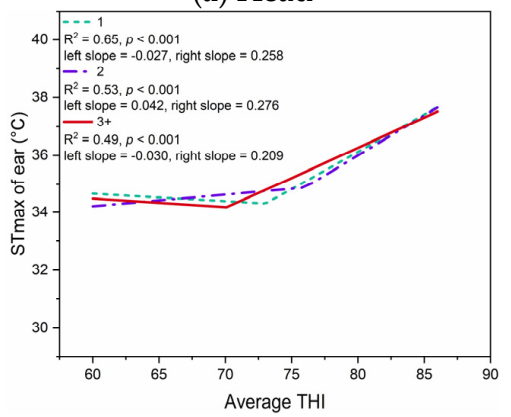

(d) Ear

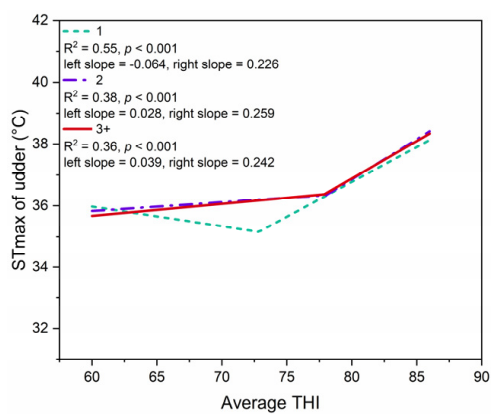

(g) Udder

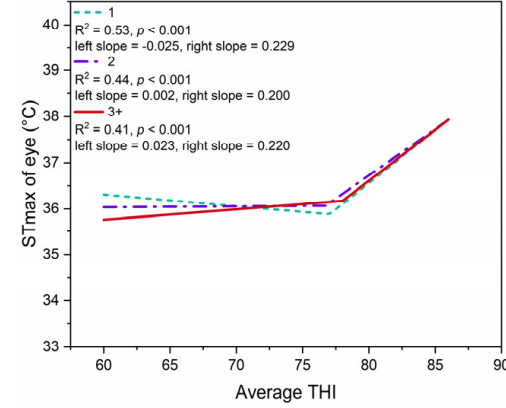

(b) Eye

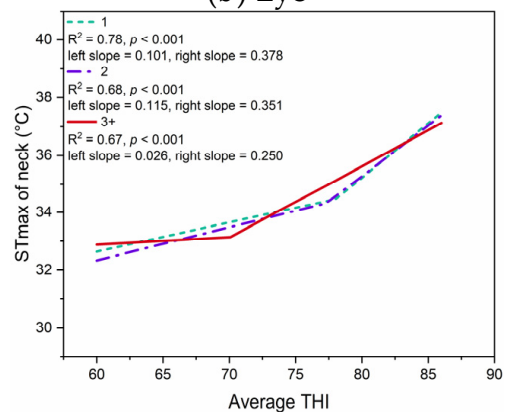

(e) Neck

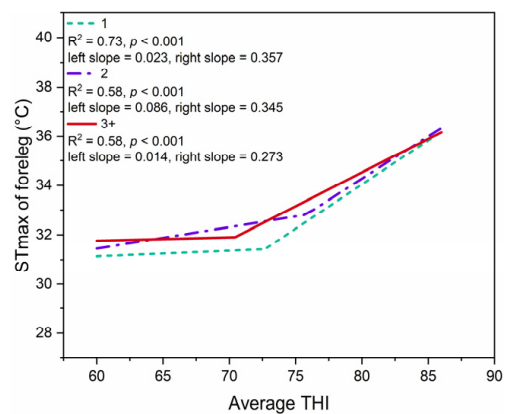

(h) Foreleg

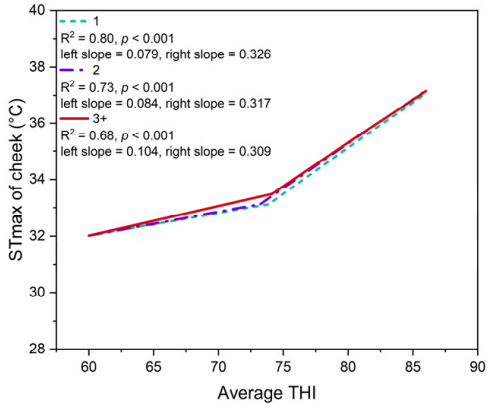

(c) Cheek

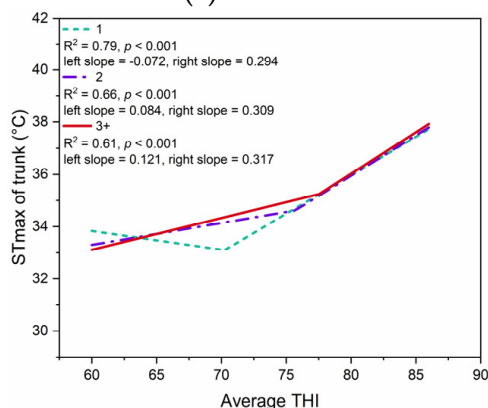

(f) Trunk

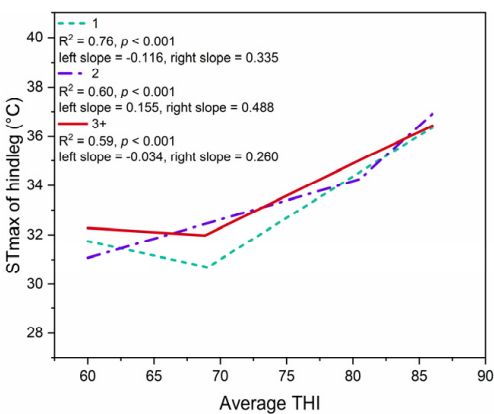

(i) Hindleg

Figure 7. Relationship between maximum surface temperature (STmax) of (a) head, (b) eye, (c) cheek, (d) ear, (e) neck, (f) trunk, (g) udder, (h) foreleg, and (i) hindleg and average THI (average of each measurement) considering lactation number (1, 2, and 3+). 


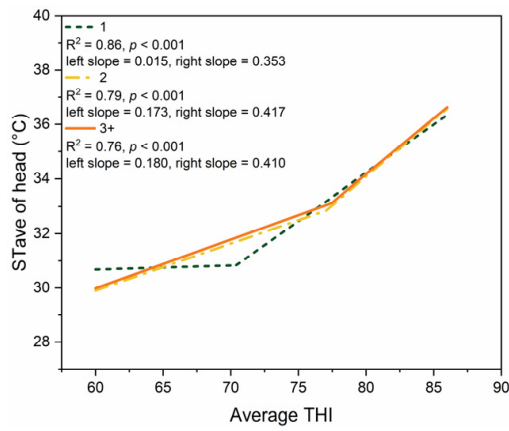

(a) Head

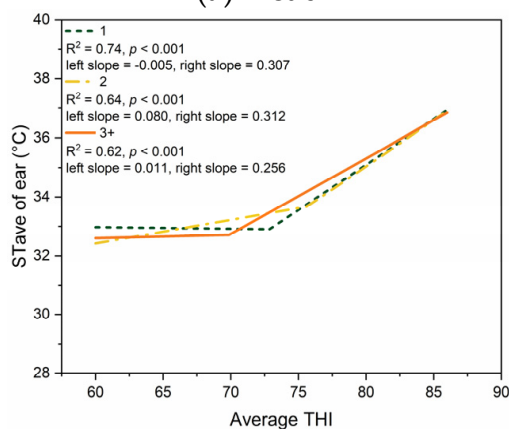

(d) Ear

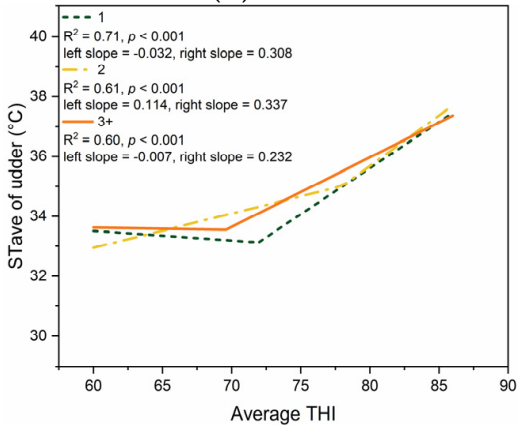

(g) Udder

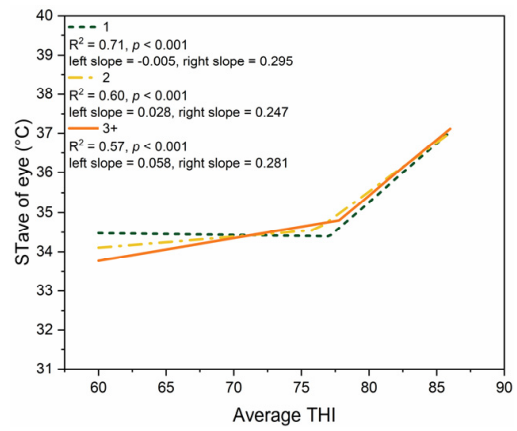

(b) Eye

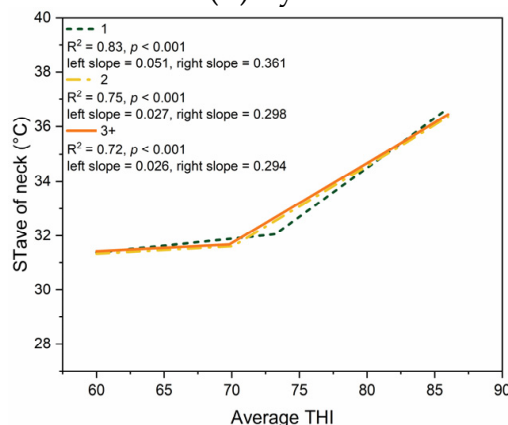

(e) Neck

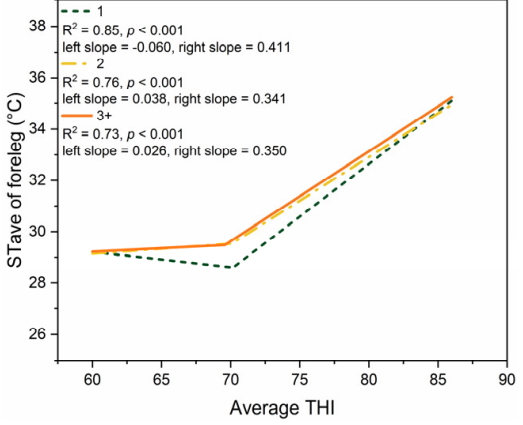

(h) Foreleg

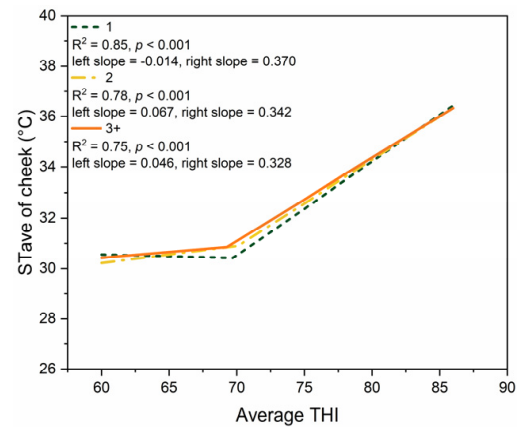

(c) Cheek

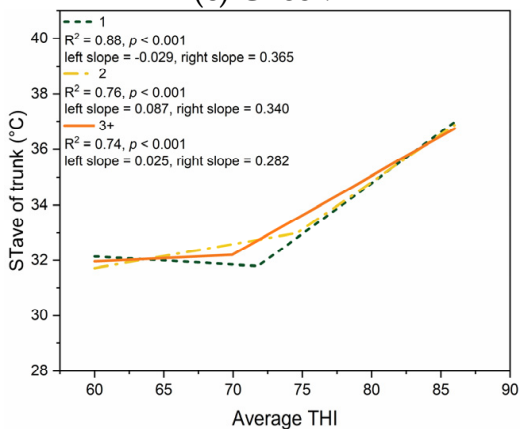

(f) Trunk

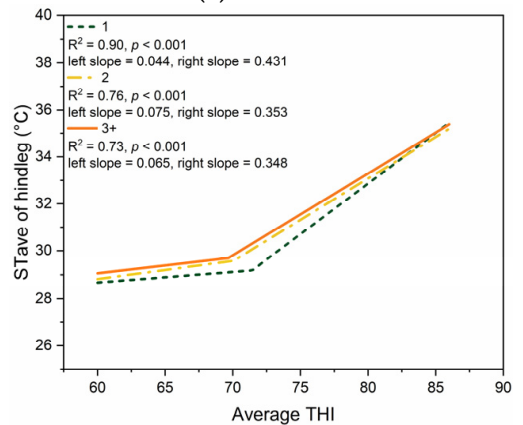

(i) Hindleg

Figure 8. Relationship between average surface temperature (STave) of (a) head, (b) eye, (c) cheek, (d) ear, (e) neck, (f) trunk, (g) udder, (h) foreleg, and (i) hindleg and average THI (average of each measurement) considering lactation number (1, 2, and $3+)$.

All the breakpoints were significant $(p<0.001)$ and are shown in Table 5. A oneway ANOVA analysis indicated that the lactation number did not significantly influence the THI breakpoints for STmax $(\mathrm{F}-\mathrm{value}=2.492$, df1 $=2, \mathrm{df} 2=24, p=0.104)$ and STave $(\mathrm{F}$-value $=1.069, \mathrm{df} 1=2, \mathrm{df} 2=24, p=0.359)$.

Table 5. THI breakpoints for maximum (STmax) and average surface temperature (STave) of the different body regions in 1st-lactation, 2nd-lactation, and $3 \mathrm{rd}^{+}$-lactation cows.

\begin{tabular}{|c|c|c|c|c|}
\hline THI Breakpoint & Body Region & 1st-Lactation ${ }^{1}$ & 2nd-Lactation ${ }^{1}$ & $3 \mathrm{rd}^{+}$-Lactation ${ }^{1}$ \\
\hline \multirow{9}{*}{ STmax } & Head & $76.7 \pm 1.2$ & $76.4 \pm 0.5$ & $77.8 \pm 0.4$ \\
\hline & Eye & $77.0 \pm 1.1$ & $76.7 \pm 0.6$ & $78.0 \pm 0.5$ \\
\hline & Cheek & $73.9 \pm 1.7$ & $73.2 \pm 0.7$ & $74.1 \pm 0.6$ \\
\hline & Ear & $73.0 \pm 1.4$ & $76.0 \pm 0.7$ & $70.1 \pm 0.8$ \\
\hline & Neck & $78.0 \pm 1.3$ & $77.3 \pm 0.6$ & $70.1 \pm 0.7$ \\
\hline & Trunk & $70.2 \pm 1.1$ & $75.7 \pm 0.7$ & $77.5 \pm 0.7$ \\
\hline & Udder & $72.8 \pm 1.4$ & $78.0 \pm 0.6$ & $73.9 \pm 0.6$ \\
\hline & Foreleg & $72.7 \pm 1.6$ & $75.8 \pm 0.7$ & $70.4 \pm 0.7$ \\
\hline & Hindleg & $69.1 \pm 1.2$ & $80.5 \pm 0.6$ & $68.8 \pm 0.7$ \\
\hline
\end{tabular}


Table 5. Cont.

\begin{tabular}{|c|c|c|c|c|}
\hline THI Breakpoint & Body Region & 1st-Lactation ${ }^{1}$ & 2nd-Lactation 1 & $3^{3} d^{+}$-Lactation ${ }^{1}$ \\
\hline \multirow{9}{*}{ STave } & Head & $70.4 \pm 1.3$ & $77.0 \pm 0.6$ & $77.4 \pm 0.6$ \\
\hline & Eye & $77.1 \pm 0.9$ & $76.1 \pm 0.5$ & $77.8 \pm 0.5$ \\
\hline & Cheek & $69.7 \pm 1.3$ & $70.1 \pm 0.8$ & $69.3 \pm 0.7$ \\
\hline & Ear & $72.9 \pm 1.3$ & $75.6 \pm 0.7$ & $69.9 \pm 0.8$ \\
\hline & Neck & $73.2 \pm 1.3$ & $70.1 \pm 0.7$ & $69.8 \pm 0.6$ \\
\hline & Trunk & $71.8 \pm 0.8$ & $74.6 \pm 0.5$ & $69.9 \pm 0.6$ \\
\hline & Udder & $72.0 \pm 1.4$ & $78.0 \pm 0.7$ & $69.6 \pm 0.7$ \\
\hline & Foreleg & $70.2 \pm 1.1$ & $70.1 \pm 0.8$ & $69.6 \pm 0.6$ \\
\hline & Hindleg & $71.5 \pm 1.0$ & $70.1 \pm 0.8$ & $69.7 \pm 0.7$ \\
\hline
\end{tabular}

${ }^{1}$ 1st-lactation represents lactation number $=1$, 2nd-lacation represents lactation number $=2$, and $3 \mathrm{rd}^{+}$-lactation represents lactation number $\geq 3$.

\section{Discussion}

Rectal temperature is a primary physiological indicator of thermal status in dairy cows. In this study, the correlation coefficients between surface temperature and rectal temperature ranged between 0.57 and 0.71 , which generally agreed with previous studies. Researchers also previously performed investigations on the ST of different body regions. However, there remained no consistent conclusion regarding the best region for indicating the rectal temperature or thermal status of cows from these studies, as they were undertaken with different experimental conditions (e.g., differences in climate conditions, experimental period, sample number, breed of cattle, and degree of heat stress acclimatization). Salles et al. [13] observed the ST of 24 Jersey dairy heifers in a thermoneutral environment over 35 days and found that the ST of the forehead exhibited a strong association with the rectal temperature. Peng et al. [14] investigated the ST in Chinese Holstein cows $(n=488)$ in a naturally ventilated barn and reported that the ST of the forehead acted as a relatively reliable region to indicate rectal temperature. In a study conducted in tropical climates with 38 lactating Holstein crossbreeds, Daltro et al. [17] reported that the correlation (0.74) between the ST of the lateral region of the udder and rectal temperature is the highest. The authors suggested the ST of this region as an indicator of thermal comfort. Regardless of the differences in suggested ST variables, this study as well as the previous studies, have consistently demonstrated strong associations between some of the ST variables and the internal temperature of cows. This provides a foundation for identifying critical THI thresholds, through detecting the changes in the ST.

In this study, we identified critical THI thresholds based on the STmax and the STave, respectively. We found that the thresholds for STaves (a mean of $72.6 \mathrm{THI}$ ) were significantly smaller than those for STmax (a mean of $76.1 \mathrm{THI}$ ), which indicates that the STave responded to changes in environmental conditions at a faster rate than the STmax. Such a finding did not agree with Macmillian et al. [28], who found the STave to be not very sensitive to change. It is well known that the STave is the average of all the pixel temperatures in the image or region while the STmax is the hottest pixel temperature. The STmax tends to occur in areas with greater blood flow or less hair. In this context, the STave is more representative of the overall region than the STmax. Additionally, our results showed that the STave showed higher coefficients of determination and correlations with rectal temperature than the STmax. Therefore, it can be inferred that the STave reflects the internal temperature better than the STmax, although it is not as accurate in recording the internal temperature as STmax with regard to its value. Based on this, the STave is more appropriate to determine the critical THI threshold defined by ST, which is the main concern of this study.

As mentioned, the critical THI thresholds reported in previous studies were based on common physiological, behavioral, or productive indicators. To our knowledge, no definitive critical THI thresholds based on ST existed. Consequently, we compared the thresholds for ST with those defined by other variables, such as rectal temperature, respiration rate, rumination time, and milk production. In previous studies of Armstrong et al. [32] the THI 
threshold of 72 from was used to classify heat stress in dairy cows. Zimbelman et al. [33] evaluated the impact of THI on changes in the milk production of cows in the southern US and declared the critical threshold as 68 THI. Based on this, Collier et al. [34] proposed revised heat stress categories. Recently, some researchers demonstrated that heat stress could develop in low THI environments and thus proposed the updated critical THI thresholds. Heinicke et al. [30] reported that heat load thresholds determined by piecewise models were 67 THI for lactating dairy cows in a temperate climate in Germany. The authors defined the thresholds according to the changes in activity traits of cows, including numbers of lying/standing bouts, total lying/standing time, and the duration of lying bouts. Pinto et al. [11] conducted a study with 139 multiparous cows and found that the critical THI thresholds for respiration rate, heart rate, and rectal temperature were 70, 72, and 70, respectively. A study conducted in a subtropical climate in the US, performed by Dado-Senn et al. [9], showed that the thresholds were $67 \mathrm{THI}$ for rectal temperature and 65 for respiration rate in Holstein dairy calves exposed to heat stress. In the present study, the thresholds ranged between 69 and 77, depending on the body region. The lowest value (i.e., 69 THI) we found was the intermediate value of these published thresholds. The highest value proved to be similar to the findings of Ouellet et al. [10], who reported that the critical THI thresholds for respiration rate and rectal temperature were 77 for dry Holstein cows that were kept in the shade in subtropical environments. Therefore, our study shows that ST can serve as a physiological indicator to determine critical THI thresholds. However, choosing the appropriate ST variables is a prerequisite to achieve this.

Among the investigated ST variables, the STmax and STave of the cheek presented the closest relationship (i.e., coefficient of determination and Pearson's $r$ ) with rectal temperature compared to other body regions. More importantly, both the THI thresholds for STmax (73.6) and STave (69.1) of the cheek were found to be the lowest. Given that a lower THI threshold is recommended for alerting for heat stress, the STave of the cheek could be a potential prior ST variable to determine critical THI thresholds. In previous literature, Peng et al. [14] reported that the STave of the cheek is one of the suitable variables that can reflect the changes of ST. Montaholi et al. [35] found that the ST of the cheek correlated well with the feed efficiency in beef steers. Macmillan et al. [28] reported that the average ST of the cheek was more appropriate for identifying sick early postpartum cows than rectal temperature. Clear explanations regarding the reason why the ST of the cheek is suitable for evaluating heat stress, feeding efficiency, and for diagnosing diseases, have not been given in the published literature. Our study indicated that the ST of the cheek could respond to environmental changes earlier than other regions.

There were few studies that investigated the linkage between the lactation stage and THI thresholds. In this study, we observed that the stage of lactation significantly influenced the thresholds for STmax, but the significance was not found for the thresholds for STave. These findings were partially consistent with the study from Müschner-Siemens et al. [24], who found that the cows in early-lactation, mid-lactation, and late-lactation had the same THI threshold of 52, determined by daily rumination time. Our previous study reported that the THI thresholds for rectal temperature and respiration rate were 68 and 65 in earlyand mid-lactation cows and 70 and 67 in late-lactation cows [36]. However, we did not test its significance in our previous study. For our current study, the insignificant association between the stage of lactation and thresholds for STave could be supported by a recent study from Osei-Amponsah et al. [37], who reported that the stage of lactation had no significant effect on respiration rate, panting score, and ST. Besides, earlier studies [38,39] found that mid-lactation cows were more adversely affected by summer conditions, followed by lateand early-lactation cows, which corresponds to our findings that mid-lactation cows had a lower mean thresholds for STmax (75 THI) than early-lactation cows (79 THI). It should be noted that some cows could transition from the previous lactation stage to the next stage during the study period. This could lead to a failure in detecting the significance of the lactation stage. 
In this study, we evaluated the effects of lactation numbers on THI thresholds for ST. Relevant studies on the subject are still lacking. Previous research reported that milk losses in multiparous cows were higher than those in primiparous cows due to heat stress $[23,40]$. In this context, 3rd-lactation cows and multiparous cows were more susceptible to higher thermal conditions and should show significantly lower thresholds for ST than 2nd-lactation and 1st-lactation cows. However, in our result the significance of the lactation number on thresholds for ST was not detected. According to CIGR [41], the heat production of lactating cows largely depends on body weight and milk yield. If the body weight is similar and the thermal environment is the same, milk yield will be the determinant factor for the heat load in cows. Therefore, the missing significances can be explained by the smaller differences in average daily milk yield among the groups.

As mentioned earlier, critical THI thresholds defined by ST have not been reported yet. We identified thresholds for STmax and STave through piecewise models. However, caution must still be applied when our findings are extrapolated to other situations. This is because we cannot lose sight of the effects other individual factors on the results of the thresholds, such as the adaptation of the genetics of cows [24].

\section{Conclusions}

This study identified the critical THI threshold for the STmax and the STave of different body regions (head, eye, cheek, ear, neck, trunk, udder, foreleg, and hindleg) in lactating dairy cows for the first time. We found that the STave was a more appropriate measure to define thresholds than STmax. The threshold for the STave of the cheek (69.1 THI) was lowest among the thresholds, indicating that the STave of the cheek could be a prior ST variable to determine critical THI thresholds. The lactation stage only significantly affected the thresholds for STmax, and the lactation number has no significant effect on the thresholds for both STmax and STave. Our findings highlighted the potential use of ST variables in defining the critical THI threshold. Additionally, our study has shown that infrared technology has potential applications in assessing environmental heat stress on dairy cows remotely, which is helpful for obtaining rational decision-making information under commercial conditions. Further studies investigating the factors related to the thresholds of ST are still needed.

Author Contributions: Conceptualization, methodology, software, formal analysis, investigation, data curation, visualization, writing—original draft preparation, G.Y.; writing—review and editing, supervision, funding acquisition, H.L.; supervision, funding acquisition, Z.S. All authors have read and agreed to the published version of the manuscript.

Funding: This research was funded by the National Key R \& D program Inter-governmental/Hong Kong, Macao and Taiwan key projects (2019YFE0103800) and the China Agriculture Research System of MOF and MARA.

Institutional Review Board Statement: The study protocol was approved by the China Agricultural University Department of Agricultural Structure and Bioenvironmental Engineering Animal Ethics Committee (20200625).

Informed Consent Statement: Not applicable.

Data Availability Statement: The data presented in this study are available from the corresponding author on reasonable request.

Conflicts of Interest: The authors declare no conflict of interest.

\section{References}

1. Dikmen, S.; Hansen, P.J. Is the temperature-humidity index the best indicator of heat stress in lactating dairy cows in a subtropical environment? J. Dairy Sci. 2009, 92, 109-116. [CrossRef]

2. Hoffmann, G.; Herbut, P.; Pinto, S.; Heinicke, J.; Kuhla, B.; Amon, T. Animal-related, non-invasive indicators for determining heat stress in dairy cows. Biosyst. Eng. 2020, 199, 83-96. [CrossRef]

3. Polsky, L.; von Keyserlingk, M.A.G. Effects of heat stress on dairy cattle welfare. J. Dairy Sci. 2017, 100, 8645-8657. [CrossRef] 
4. Godyń, D.; Herbut, P.; Angrecka, S. Measurements of peripheral and deep body temperature in cattle-A review. J. Therm. Biol. 2019, 79, 42-49. [CrossRef]

5. $\quad$ Eigenberg, R.A.; Brown-Brandl, T.M.; Nienaber, J.A.; Hahn, G.L. Dynamic response indicators of heat stress in shaded and non-shaded feedlot cattle, part 2: Predictive relationships. Biosyst. Eng. 2005, 91, 111-118. [CrossRef]

6. Kovács, L.; Kézér, F.L.; Ruff, F.; Jurkovich, V.; Szenci, O. Heart rate, cardiac vagal tone, respiratory rate, and rectal temperature in dairy calves exposed to heat stress in a continental region. Int. J. Biometeorol. 2018, 62, 1791-1797. [CrossRef]

7. Wang, X.; Gao, H.; Gebremedhin, K.G.; Bjerg, B.S.; van Os, J.; Tucker, C.B.; Zhang, G. A predictive model of Equivalent Temperature Index for dairy Cattle (ETIC). J. Therm. Biol. 2018, 76, 165-170. [CrossRef]

8. Kovács, L.; Kézér, F.L.; Póti, P.; Boros, N.; Nagy, K. Short communication: Upper critical temperature-humidity index for dairy calves based on physiological stress variables. J. Dairy Sci. 2020, 103, 2707-2710. [CrossRef] [PubMed]

9. Dado-Senn, B.; Ouellet, V.; Dahl, G.E.; Laporta, J. Methods for assessing heat stress in preweaned dairy calves exposed to chronic heat stress or continuous cooling. J. Dairy Sci. 2020, 103, 8587-8600. [CrossRef]

10. Ouellet, V.; Toledo, I.M.; Dado-Senn, B.; Dahl, G.E.; Laporta, J. Critical temperature-humidity index thresholds for dry cows in a subtropical climate. Front. Anim. Sci. 2021, 2, 28. [CrossRef]

11. Pinto, S.; Hoffmann, G.; Ammon, C.; Amon, T. Critical THI thresholds based on the physiological parameters of lactating dairy cows. J. Therm. Biol. 2020, 88, 102523. [CrossRef]

12. Herbut, P.; Angrecka, S.; Walczak, J. Environmental parameters to assessing of heat stress in dairy cattle-A review. Int. J. Biometeorol. 2018, 62, 2089-2097. [CrossRef]

13. Salles, M.S.V.; da Silva, S.C.; Salles, F.A.; Roma, L.C.; El Faro, L.; Bustos Mac Lean, P.A.; Lins de Oliveira, C.E.; Martello, L.S. Mapping the body surface temperature of cattle by infrared thermography. J. Therm. Biol. 2016, 62, 63-69. [CrossRef] [PubMed]

14. Peng, D.; Chen, S.; Li, G.; Chen, J.; Wang, J.; Gu, X. Infrared thermography measured body surface temperature and its relationship with rectal temperature in dairy cows under different temperature-humidity indexes. Int. J. Biometeorol. 2019, 63, 327-336. [CrossRef]

15. Uddin, J.; Phillips, C.J.C.; Auboeuf, M.; McNeill, D.M. Relationships between body temperatures and behaviours in lactating dairy cows. Appl. Anim. Behav. Sci. 2021, 241, 105359. [CrossRef]

16. Uddin, J.; McNeill, D.M.; Lisle, A.T.; Phillips, C.J.C. A sampling strategy for the determination of infrared temperature of relevant external body surfaces of dairy cows. Int. J. Biometeorol. 2020, 64, 1583-1592. [CrossRef]

17. Daltro, D.D.S.; Fischer, V.; Alfonzo, E.P.M.; Dalcin, V.C.; Stumpf, M.T.; Kolling, G.J.; da Silva, M.V.G.B.; McManus, C. Infrared thermography as a method for evaluating the heat tolerance in dairy cows Infrared thermography as a method for evaluating the heat tolerance in dairy cows. R. Bras. Zootec. 2017, 46, 374-383. [CrossRef]

18. Romanovsky, A.A. Skin temperature: Its role in thermoregulation. Acta. Physiol. 2014, 210, 498-507. [CrossRef] [PubMed]

19. Sakoi, T.; Tsuzuki, K.; Kato, S.; Ooka, R.; Song, D.; Zhu, S. Thermal comfort, skin temperature distribution, and sensible heat loss distribution in the sitting posture in various asymmetric radiant fields. Build. Environ. 2007, 42, 3984-3999. [CrossRef]

20. Djongyang, N.; Tchinda, R.; Njomo, D. Thermal comfort: A review paper. Renew. Sustain. Energy Rev. 2010, 14, 2626-2640. [CrossRef]

21. McManus, C.; Tanure, C.B.; Peripolli, V.; Seixas, L.; Fischer, V.; Gabbi, A.M.; Menegassi, S.R.O.; Stumpf, M.T.; Kolling, G.J.; Dias, E.; et al. Infrared thermography in animal production: An overview. Comput. Electron. Agric. 2016, 123, 10-16. [CrossRef]

22. Li, S.; Gebremedhin, K.G.; Lee, C.; Collier, R. Evaluation of thermal stress indices for cattle. In Proceedings of the 2009 ASABE Annual International Meeting, St. Joseph, MI, USA, 21-24 June 2009.

23. Tao, S.; Orellana Rivas, R.M.; Marins, T.N.; Chen, Y.-C.; Gao, J.; Bernard, J.K. Impact of heat stress on lactational performance of dairy cows. Theriogenology 2020, 150, 437-444. [CrossRef]

24. Müschner-Siemens, T.; Hoffmann, G.; Ammon, C.; Amon, T. Daily rumination time of lactating dairy cows under heat stress conditions. J. Therm. Biol. 2020, 88, 102484. [CrossRef] [PubMed]

25. NRC. A Guide to Environmental Research on Animals; National Academy of Sciences: Washington, DC, USA, 1971.

26. Montanholi, Y.R.; Lim, M.; Macdonald, A.; Smith, B.A.; Goldhawk, C.; Schwartzkopf-Genswein, K.; Miller, S.P. Technological, environmental and biological factors: Referent variance values for infrared imaging of the bovine. J. Anim. Sci. Biotechnol. 2015, 6, 1-16. [CrossRef]

27. Isola, J.V.V.; Menegazzi, G.; Busanello, M.; dos Santos, S.B.; Agner, H.S.S.; Sarubbi, J. Differences in body temperature between black-and-white and red-and-white Holstein cows reared on a hot climate using infrared thermography. J. Therm. Biol. 2020, 94, 102775. [CrossRef] [PubMed]

28. Macmillan, K.; Colazo, M.G.; Cook, N.J. Evaluation of infrared thermography compared to rectal temperature to identify illness in early postpartum dairy cows. Res. Vet. Sci. 2019, 125, 315-322. [CrossRef] [PubMed]

29. Yan, G.; Li, H.; Zhao, W.; Shi, Z. Evaluation of thermal indices based on their relationships with some physiological responses of housed lactating cows under heat stress. Int. J. Biometeorol. 2020, 64, 2077-2091. [CrossRef]

30. Heinicke, J.; Hoffmann, G.; Ammon, C.; Amon, B.; Amon, T. Effects of the daily heat load duration exceeding determined heat load thresholds on activity traits of lactating dairy cows. J. Therm. Biol. 2018, 77, 67-74. [CrossRef]

31. Muggeo, V. Segmented: An R package to fit regression models with broken-line relationships. $R$ News 2008, 8, $20-25$.

32. Armstrong, D.V. Heat stress interaction with shade and cooling. J. Dairy Sci. 1994, 77, 2044-2050. [CrossRef] 
33. Zimbelman, R.B.; Rhoads, R.; Rhoads, M.; Duff, G.; Baumgard, L.; Collier, R. A re-evaluation of the impact of Temperature Humidity Index (THI) and Black Globe Humidity Index (BGHI) on milk production in high producing dairy cows. In Proceedings of the Southwest Nutrition \& Management Conference, Tempe, AZ, USA, 26-27 February 2009; pp. 158-169.

34. Collier, R.; Hall, L.; Rungruang, S.; Zimbelman, R. Quantifying heat stress and its impact on metabolism and performance. In Proceedings of the 23rd Annual Ruminant Nutrition Symposium, Gainesville, FL, USA, 31 January-1 February 2012; pp. 74-84

35. Montanholi, Y.R.; Swanson, K.C.; Palme, R.; Schenkel, F.S.; Mcbride, B.W.; Lu, D.; Miller, S.P. Assessing feed efficiency in beef steers through feeding behavior, infrared thermography and glucocorticoids*. Animal 2010, 4, 692-701. [CrossRef] [PubMed]

36. Yan, G.; Liu, K.; Hao, Z.; Shi, Z.; Li, H. The effects of cow-related factors on rectal temperature, respiration rate, and temperaturehumidity index thresholds for lactating cows exposed to heat stress. J. Therm. Biol. 2021, 100, 103041. [CrossRef]

37. Osei-Amponsah, R.; Dunshea, F.R.; Leury, B.J.; Cheng, L.; Cullen, B.; Joy, A.; Abhijith, A.; Zhang, M.H.; Chauhan, S.S. Heat stress impacts on lactating cows grazing Australian summer pastures on an automatic Robotic Dairy. Animals 2020, 10, 869. [CrossRef]

38. Perera, K.S.; Gwazdauskas, F.C.; Pearson, R.E.; Brumback, T.B. Effect of season and stage of lactation on performance of Holsteins. J. Dairy Sci. 1986, 69, 228-236. [CrossRef]

39. Maust, L.E.; Mcdowell, R.E.; Hooven, N.W. Effect of summer weather on performance of Holstein cows in three stages of lactation. J. Dairy Sci. 1972, 55, 1133-1139. [CrossRef]

40. Adriaens, I.; van den Brulle, I.; D'Anvers, L.; Statham, J.M.E.; Geerinckx, K.; de Vliegher, S.; Piepers, S.; Aernouts, B. Milk losses and dynamics during perturbations in dairy cows differ with parity and lactation stage. J. Dairy Sci. 2021, 104, 405-418. [CrossRef] [PubMed]

41. CIGR. Heat and moisture production at animal and house levels. In Fourth Report of CIGR Working Group on Climatization of Animal Houses; Pedersen, S., Sällvik, K., Eds.; Research Centre Bygholm, Danish Institute of Agricultural Sciences: Horsens, Denmark, 2002. 